\title{
ANTIBACTERIAL EFFECT OF DIFFERENT TYPES OF GLASS IONOMER RESTORATIONS ON STREPTCOCUS MUTANS
}

\author{
Rasha Raafat*
}

\begin{abstract}
Statement of problem: failure of any restorative system is most frequently caused by caries; it would be advantageous if the restoration possessed antibacterial properties.

Objective: The purpose of this study was to assess the inhibitory activity of three different glass ionomer restorative systems against streptococcus mutans using the agar diffusion test.

Material and methods: The antibacterial activity of three types of glass ionomer restorations (Ketac Fil Plus;3M, Ketac Silver Aplicap; 3M, Chemfil rock; Dentsply) were evaluated against Streptococcus mutans using the agar inhibition test. Zone of inhibition on Mitis salivarius agar plates was measured after 24 hours, 48 hours and one week. Data were explored for normality using Kolmogorov-Smirnov test of normality. And one way analysis of variance (ANOVA) test was used to compare between groups. This was followed by Tukey post hoc test for multiple pairwise comparisons.
\end{abstract}

Results: At 24 hours Statistically significant largest zone of inhibition was observed with Ketac fil plus with no statistically significant difference between Ketac silver and Chemfil rock whereas at 48 hours and one week no statistically significant difference among all the tested groups.

Conclusions: Within the limits of this in-vitro study it can be concluded that conventional GIC had antibacterial effect against the streptococcus mutans better than silver zinc reinforced types of GICs especially within the first 24 hours. Also addition of new elements as silver or zinc for GICs affect negatively on their anti-bacterial role as it increase their strength and hardness with decreasing solubility so limited leach out of ions from restorations.

\section{INTRODUCTION}

Glass ionomer cements (GICs) have been introduced in dentistry in the mid-seventies ${ }^{(1)}$ having some favorable properties such as a chemical bond to enamel and dentin, with coefficient of thermal expansion almost equal to natural tooth tissues, beside its ability to release fluoride ions over a significant amount of time ${ }^{(2,3)}$. As a result, GICs are considered as biomaterials that may prevent (2) dental caries and its progression. It is known that both restorative materials and oral

* Lecturer of Conservative Dentistry, Faculty of Dentistry, Cairo University, Egypt. 
bacteria are mainly responsible for the restoration failure ${ }^{(4)}$. Secondary caries may occurs at the interface between the restoration and the tooth structures as a result of demineralization and due to invasion of plaque bacteria (acid producing bacteria) such as Streptococcus mutans (S. mutans) ${ }^{(5)}$. Fluoride plays a significant role in dentistry and is influential in the treatment of incipient dental caries as well as prevention for future dental caries ${ }^{(6,3)}$. GICs are found to have cariostatic and antibacterial effect due to release of fluoride, which is believed to help reduce demineralization, enhance remineralization and inhibit microbial growth ${ }^{(5,6)}$. Researches and clinical surveys found that Streptococcus mutans is considered the major contributing microorganism involved in the dental caries ${ }^{(6)}$. Also it is documented that Secondary caries remains as one of the leading causes of replacement of restorations due to the colonization of bacterial biofilm at the tooth-restoration interface $(7,6)$ even with GICs failure ${ }^{(8)}$. Furthermore, it is indicating that the fluoride-release from GICs is not potent enough to inhibit bacterial growth or combat bacterial destruction ${ }^{(8)}$. Fluoride release seems to be the most probable reason for the inhibitory effect on acid production. Fluoride availability from glass ionomer is $\mathrm{pH}$ controlled, the rate-controlling factors being salivary phosphate and proteins ${ }^{(9)}$. Also, Shashibhushan et al ${ }^{(10)}$ reported that there is a direct correlation between the amount of fluoride release and the antibacterial activity. As the low $\mathrm{pH}$ of glass ionomer cements while setting may contribute more totheir antimicrobial properties than their fluoride-leaching capabilities ${ }^{(9)}$. Recent trials have been made on improving antibacterial activities of GICs, focusing on incorporated antibacterial agents such as antibiotics, zinc ions, silver ions, iodine and chlorhexidine to improve their anti-cariogenic property ${ }^{(11)}$. The study null hypotheses were that (I) Streptococcus mutans is not affected by the release of fluoride, (II) the release of other different incorporated ions such as silver or zinc not affects the Streptococcus mutans activity.

\section{MATERIALS AND METHODS}

\section{Specimen preparation}

Thirty standardized specimens were prepared from a three different groups of glass ionomer cements 10 each (ketac fil plus aplicap glass ionomer restorative, 3M; group A), (ketac Silver aplicap reinforced glass ionomer restorative, 3M; group B), Chemfil rock restorative, Dentsply; group C). For preparation of a single specimen, a standardized amount of each material was placed into a custom made steel mold with a diameter of $6.0 \mathrm{~mm}$ and height of $2.0 \mathrm{~mm}$, condensed against a glass slab and covered with a cellulose acetate strip (Mylar1) and finger pressure was applied to form a flat surface. Then materials were allowed to set for the manufacturer's recommended setting time. Specimens were removed and then gently refined using surgical scalpels to remove any flash material from the edges.

\section{Microbiological procedures}

Agar Plate Diffusion Test was used to assessed the antibacterial activity of different GICs against the streptococcus mutans (S. mutans). S. mutans (UA159) was obtained from the culture stock of the Department of Microbiology and Immunology of Cairo University. The indicator strain was first grown on Mitis salivarius agar plates at $37^{\circ} \mathrm{C}$ for 48 $\mathrm{h}$ in a $10 \% \mathrm{CO} 2$ incubator (BBL Gas Pak, Becton Dickinson USA). Subsequently, single colonies were inoculated into $5 \mathrm{~mL}$ of Brain Heart Infusion (BHI) broth and incubated at $37^{\circ} \mathrm{C}$ for $24 \mathrm{~h}$ to form a suspension (inoculum). In each sterilized Petri dish $(20 \times 100 \mathrm{~mm})$, a base layer containing $15 \mathrm{~mL}$ of BHI agar mixed with $300 \mathrm{~mL}$ of each inoculum was prepared. After solidification of the culture medium, then specimens of each testing material were placed in separate agar plate marked for each material fig (1). The plates were incubated at $37{ }^{\circ} \mathrm{C}$ for 24 hours, (all procedures carried out at anaerobic jar). Zones of bacterial growth inhibition were recorded in millimeters $(\mathrm{mm})$ using a digital caliper. Measurements were taken at the greatest distance between two points at the outer limit of 
the inhibition halo formed around the specimen. This measurement was taken after 24 hours, 48 hours and 1 week. A mean and standard deviation were determined per group. Data were explored for normality using Kolmogorov-Smirnov test of normality. And one way analysis of variance (ANOVA) test was used to compare between groups. This was followed by Tukey post hoc test for multiple pairwise comparisons.

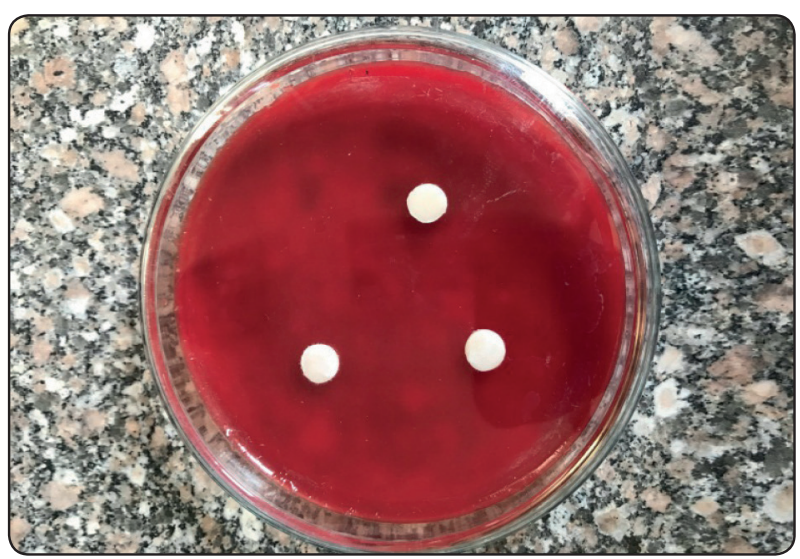

Fig. (1) : specimens planted in agar plate

\section{RESULTS}

At 24 hours, the greatest mean value was recorded in group (1) Ketac fill, whereas the lowest mean was recorded in group (2) ketac silver. The difference was extremely statistically significant $(\mathrm{p}<0.0001)$. And there was no significant difference between group (2) (Ketac silver) and group (3) (chemi-fill rock). At 48 hours, the greatest mean value was recorded in group (3) chemi-fill rock, whereas the lowest mean was recorded in group (2) ketac silver. But the difference between the 3 groups was not statistically significant $(\mathrm{p}=0.381)$. At 1 week, the greatest mean value was recorded in group (3) chemi-fill rock, whereas the lowest mean was recorded in group (2) ketac silver. Also the difference between the three groups was not statistically significant ( $\mathrm{p}=0.206)$, (Table 1, Fig.1). All groups revealed a decrease in the bacterial inhibition zone by time. This difference by time was only statistically significant in group (1) (Ketac fill) where $\mathrm{p}<0.0001$. Whereas no significant difference between 48 hours and one week groups.

TABLE (1) Bacterial inhibition zone ( $\mathrm{mm}$ ) in different groups of Glass ionomer

\begin{tabular}{|c|c|c|c|c|c|c|c|c|c|c|}
\hline \multirow{2}{*}{$\stackrel{\mathscr{E}}{\Xi}$} & \multirow[t]{2}{*}{ Groups } & \multirow{2}{*}{ Mean } & \multirow{2}{*}{$\begin{array}{c}\text { Std. } \\
\text { Deviation }\end{array}$} & \multirow{2}{*}{$\begin{array}{l}\text { Std. } \\
\text { Error }\end{array}$} & \multicolumn{2}{|c|}{$\begin{array}{l}95 \% \text { Confidence } \\
\text { Interval for Mean }\end{array}$} & \multirow{2}{*}{ Min } & \multirow{2}{*}{ Max } & \multirow{2}{*}{ F value } & \multirow{2}{*}{ Pvalue } \\
\hline & & & & & $\begin{array}{l}\text { Lower } \\
\text { Bound }\end{array}$ & $\begin{array}{l}\text { Upper } \\
\text { Bound }\end{array}$ & & & & \\
\hline \multirow{3}{*}{$\frac{\mathscr{E}}{\stackrel{\Xi}{\Xi}}$} & Ketac fill (gp1) & $22.50^{\mathrm{a}}$ & 1.65 & 0.52 & 21.32 & 23.68 & 20.00 & 25.00 & \multirow{3}{*}{14.112} & \multirow{3}{*}{$0.000 *$} \\
\hline & Ketac silver (gp2) & $19.90^{\mathrm{b}}$ & 0.99 & 0.31 & 19.19 & 20.61 & 18.00 & 21.00 & & \\
\hline & Chemi-fill rock (gp3) & $20.30^{\mathrm{b}}$ & 0.67 & 0.21 & 19.82 & 20.78 & 19.00 & 21.00 & & \\
\hline \multirow{3}{*}{ 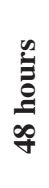 } & Ketac fill (gp1) & 20.40 & 0.70 & 0.22 & 19.90 & 20.90 & 20.00 & 22.00 & \multirow{3}{*}{1.000} & \multirow{3}{*}{$0.381^{\mathrm{ns}}$} \\
\hline & Ketac silver (gp2) & 20.00 & 0.82 & 0.26 & 19.42 & 20.58 & 19.00 & 21.00 & & \\
\hline & Chemi-fill rock (gp3) & 20.50 & 0.97 & 0.31 & 19.80 & 21.20 & 19.00 & 22.00 & & \\
\hline \multirow{3}{*}{ 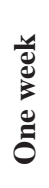 } & Ketac fill (gp1) & 19.90 & 0.57 & 0.18 & 19.49 & 20.31 & 19.00 & 21.00 & \multirow{3}{*}{1.676} & \multirow{3}{*}{$0.206^{\mathrm{ns}}$} \\
\hline & Ketac silver (gp2) & 19.60 & 0.70 & 0.22 & 19.10 & 20.10 & 19.00 & 21.00 & & \\
\hline & Chemi-fill rock (gp3) & 20.10 & 0.57 & 0.18 & 19.69 & 20.51 & 19.00 & 21.00 & & \\
\hline
\end{tabular}

Significance level $p<0.05$, * significant, $n$ s =non-significant 


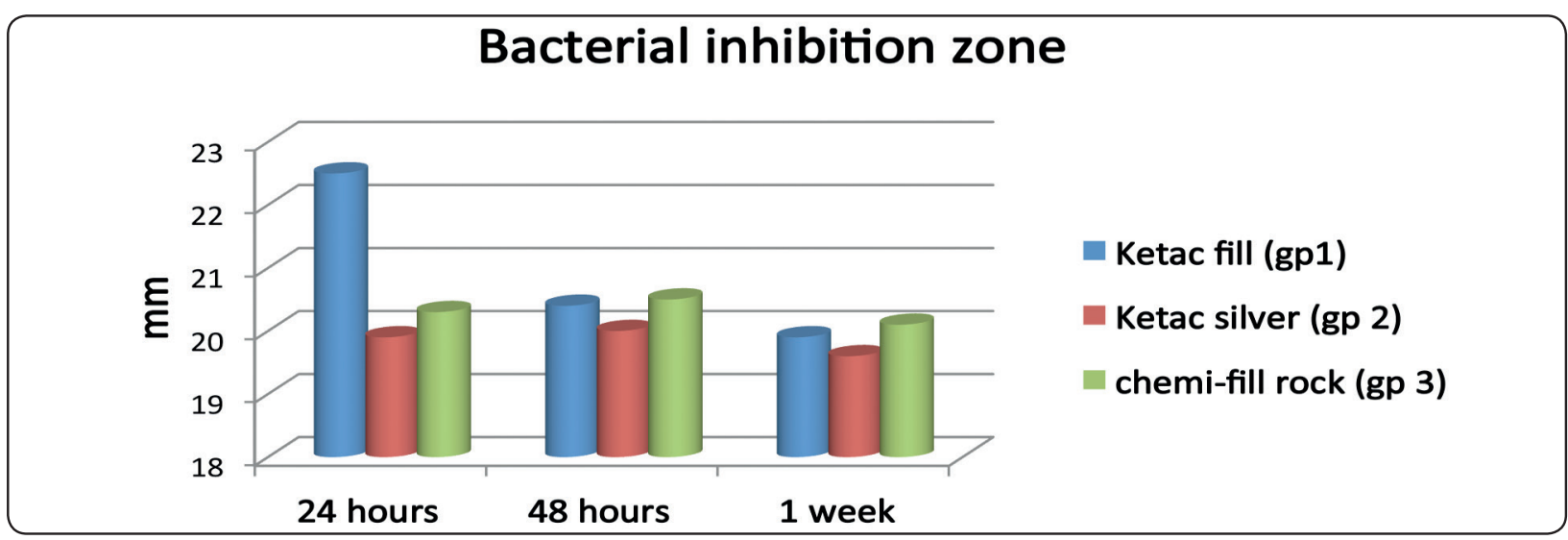

Fig. (2): Column chart showing bacterial inhibition zone ( $\mathrm{mm})$ in different groups of glass ionomer

\section{DISCUSSION}

Currently there is a growing interest in preventing or reducing biofilm formation in many biomedical areas. As secondary caries is considered one of the most frequent reasons for failure of dental restorations ${ }^{[3,12]}$, also it has often been highlighted that presence of the biofilm on the surface of dental restorations may contribute to the development of secondary caries lesions ${ }^{(3)}$. A number of studies have well documented that biofilm formation occurs on the surface of materials of different chemical nature shortly after placement in oral cavity. The influence of material surface is not well defined, but different studies suggest that several restorative materials may have antibacterial activity or may induce the growth of several bacteria ${ }^{(14)}$. Only limited information is available on bacterial adhesion especially on the surface of new restorative materials ${ }^{(13)}$. The aim of this study was to investigate and compare the surface adhesiveness of a selection of new restorative materials recently introduced in clinical practice to Streptococcus mutans, in order to ascertain possible differences ${ }^{(14)}$. Thus the aim of the present laboratory study was to elucidate the potency of the antibacterial effect of various types of GICs on Streptococcus mutans. The antibacterial effect in the present study was observed with respect to Streptococcus mutans, which is documented as the most common caries-related microorganism. ${ }^{(15)}$. Also the agar plate's diffusion method is used in this study as it is considered the only way to assess the prolonged antibacterial activity of any materials by the direct contact between bacteria and the restoration ${ }^{(13,15)}$. Regarding the results of this study, measuring the inhibition zone around each different type of the GIGs, showed that, at 24 hours the greatest value was recorded for group one (Ketac fil plus) that may be attributed to its fluoride content release. As fluoride ions causes inhibition of growth rate and growth levels of S. mutans. This was in agreement with the results of $(16,17$, and 6$)$. Who stated that Glass ionomers have the ability to release fluoride ions, which is based on diffusion based process and its antibacterial effect performed through microbial growth and metabolism inhibition. On other hand, some researchers suggested that biofilm formation and decreasing in number of S.mutans is not necessarily reduced on fluoride-releasing GICs ${ }^{(3,18)}$. For the other two groups of GICs, (ketac silver aplicap) and (chemfil rock), there was no statistically significant difference for their readings. In Despite of the Chemfil rock GI group recorded values greater than Ketac silver group which may be explained by its high zinc content of this type of glass ionomer (zinc-reinforced glass ionomer) which characterized by its potent anti-bacterial activity. This was in agreement with ${ }^{(15)}$ that has 
been suggested that GICs containing zinc-are more effective in microbial inhibition due to the direct effect of zinc particles and the cationic effect of the zinc. ${ }^{(19) \text { and (20) }}$ also found that zinc ions released by glass ionomer cements can interfere with substrate transport into the cell and so block important enzyme functions ${ }^{(20)}$. while for the Ketac silver group showed the least values among all the groups through the different testing times at 24, 48 hours and after week. may be explained by increasing the strength property of material by addition of different types of filler, as silver, causing decreasing in solubility of the material with no diffusion of antibacterial components from the restoration. For the both types of reinforced GICs either; silverreinforced (group 2) and zinc-reinforced (group 3) showed low antibacterial effect as compared to conventional GIC as the silver or zinc were added to these material for improvement of strength and wear resistance rather than for antibacterial reasons. This may confirm that the cement specimens are stable with low solubility in an aqueous environment and do not excrete sufficient antibacterial substances to the surrounding media to affect the bacterial growth. This was in accordance with ${ }^{(21)}$ who stated that the amount of fluoride release has been related to the composition and the setting reaction of the material. The high-strength conventional GICs with improving their mechanical properties can result in decreased solubility and fluoride liberation. At 48 hours and after one week, all the groups showed decreasing in their antibacterial effect but with non-statistically significant values which may be explained by The fluoride release from resinmodified glass-ionomers is high, immediately after hardening of the restoration (within 24 hours) due to initial fluoride burst effect, followed by constant slow release of fluoride for weeks ${ }^{(22)}$. This was in agreement with ${ }^{(23)}$ that explained the decrease antibacterial effect of GICs to the development of a complex buffer solution containing mainly calcium and aluminum by GIC materials ${ }^{(5)}$, which able to significantly move the $\mathrm{pH}$ of the solution closer to a neutral $\mathrm{pH}$, as lead to decrease the fluoride release level. So a greater fluoride release was observed over the first 48 hours of the bacteria/GIC interaction. Another explanation, the high initial level of F- release may be caused by the superficial rinsing effect and by glass particles reacting with the polyalkenoate acid during the setting reaction. Otherwise, the continuous F- release during the experimental period occurred because of the fluoride ability to diffuse through cement pores and fractures, which occurs with a longer cement contact with the storage media ${ }^{(23)}$.

\section{CONCLUSIONS}

Within the limits of this in-vitro study it can be concluded that conventional GIC had antibacterial effect against the streptococcus mutans better than silver zinc reinforced types of GICs especially within the first 24 hours. Also addition of new elements as silver or zinc for GICs affect negatively on their anti-bacterial role as it increase their strength and hardness with decreasing solubility so limited leach out of ions from restorations.

\section{REFERENCES}

1. Mount G.J., Hume W.R., Ngo H.C., Wolff M.S. (Eds.), Preservation and Restoration of Tooth Structure, Knowledge Book and Software Cop., Sandgate (Qld), 2005, pp. $139-168$.

2. Skartveit L., Tveit B., Total B., Øvrebø R., Raadal M., In vivo fluoride uptake in enamel and dentin fluoride from containing materials, J. Dent. Child. 57 (1990) 97-100.

3. Hahnela S., Ionescub A., Cazzanigab G., Ottobellib M., Brambillab E., Biofilm formation and release of fluoride from dental restorative materials in relation to their surface properties. J. of Dentistry 60 (2017) 14-24.

4. Guggenheimer J, Moore PA. Xerostomia: etiology, recognition and treatment. J Am Dent Assoc 2003; 134:61-9.

5. Ship JA, Pillemer SR, Baum BJ. Xerostomia and the geriatricpatient. J Am Geriatr Soc 2002; 50:535-43. 
6. Jennifer O. S., Erik J. M., Wen L., Rosalia L. B., Howard W. R., Kraig S. V., Effect of surface treatments on the mechanical properties and antimicrobial activity of desiccated glass ionomers. Dental material 32 (2 016 ) 1343-1351.

7. Brunthaler A, König F, Lucas T, Sperr W, Schedle A., Longevity of direct resin composite restorations in posterior teeth: a review. Clinical Oral Invest 2003:63-70.

8. Xiea D., Wenga Y., Guoa X., Zhaoa J., Richard L. G., Zheng C., Preparation and evaluation of a novel glass-ionomer cement with antibacterial functions. Dental materials 27 (2011) 487-496.

9. Josna V. Y., Sharada R.J., Suhasini K., Hema Ch. I., Vamsi K. Ch., Comparative Evaluation of the Antimicrobial Properties of Glass Ionomer Cements with and without Chlorhexidine Gluconate. International Journal of Clinical Pediatric Dentistry, 2016;9(2):99-103.

10. Shashibhushan KK, Basappa N, Subba Reddy VV, Comparison of antibacterial activity of three fluorides and zinc releasing commercial glass ionomer cements on strains of mutans streptococci: an in vitro study. J Indian Soc Pedod Prev Dent 2008; 26(Suppl 2):S56-S61.

11. Wiegand A, BuchallaW, Attin T. Review on fluoride-releasing restorative materials: fluoride release and uptake characteristics, antibacterial activity and influence on caries formation. Dent Mater 2007; 23:343-62.

12. Rasines Alcaraz M.G., Veitz-Keenan A., Sahrmann P., Schmidlin P.R., Davis D., Iheozor-Ejiofor Z., Direct composite resin fillings versus amalgam fillings for permanent or adult posterior teeth, Cochrane Database Syst. Rev. 31 (3) (2014) CD005620.

13. Guggenheim B., Gietsen E., Schupbach P., Shapiro S. Validation of an in vitro biofilm model of supra-gingival plaque. J Dent Res 2001; 80:363-70.

14. Lucio M.,Davide C.,Simona R., Maria Elena D., Lorenzo B., Carlo P., Carla R. A., Evaluation of bacterial adhesion of Streptococcus mutans on dental restorative materials. Biomaterials 25 (2004) 4457-4463.
15. Israel L., Shlomo M., Shimshon S., and Ervin I. W., Antibacterial properties of aged dental cements evaluated by direct-contact and agar diffusion tests J Prosthet Dent 2005; 93:364-71.

16. Luo J, Billington RW, Pearson GJ. Kinetics of fluoride release from glass components of glass ionomers. $\mathrm{J}$ Dent2009; 37:495-501.

17. Thanjal NK, Billington RW, Shahid S, Luo J, Hill RG, PearsonGJ. Kinetics of fluoride ion release from dental restorative glass ionomer cements: the influence of ultrasound, radiant heat and glass composition. J Mater Sci: Mater Med2010; 21:589-95.

18. Hahnel S., Mühlbauer G., Hoffmann J., Ionescu A., Bürgers R., Rosentritt M., Handel G., Häberlein I., Streptococcus mutans and Streptococcus sobrinus biofilm formation and metabolic activity on dental materials. Acta Odontol. Scand. 70 (2012) 114-121.

19. Garcia P., Cardia M., Francisconi R., Dovigo L., Spolid_ orio D., Rastelli A., Botta A., Antibacterial activity of glass ionomer cement modified by zinc oxide nanoparticles. Microsc Res Tech. 2017;80: 456-461.

20. Altenburger S., Spitzmüller B., Anderson A., Hellwig E., and Al-Ahmad A., Antimicrobial Effects of Dental Luting Glass Ionomer Cements on Streptococcus mutans. Scientific World Journal 2014, Article ID 807086, 7 pages.

21. Naik R., Dodamani A., Khairnar M., Jadhav H., Deshmukh M., Comparative assessment of antibacterial activity of different glass ionomer cements on cariogenic bacteria. rde. (2016).(41).4.278.

22. Tarasingh P., Reddy J., Suhasini K., Hemachandrika I., Comparative Evaluation of Antimicrobial Efficacy of Resin-Modified Glass Ionomers, Compomers and Giomers An Invitro Study. Journal of Clinical and Diagnostic Research. 2015, Vol-9(7): ZC85-ZC87.

23. Fucio S., de Paula A., Sardi J., Duque C., Correr-Sobrinho L., Puppin-Rontani R., Streptococcus Mutans Biofilm Influences on the Antimicrobial Properties of Glass Ionomer Cements Brazilian. Dental Journal (2016) 27(6): 681-687. 